PRINT ISSN 1119-8362

Electronic ISSN 1119-8362
Full-text Available Online at

https://www.ajol.info/index.php/jasem

http://ww.bioline.org.br/ja
J. Appl. Sci. Environ. Manage.

Vol. 24 (10) 1801-1810 October 2020

\title{
A Critique on Sustainable Cities Waste Management Predicaments; Case of Nairobi City, Kenya
}

\section{*OGUTU; FA; ${ }^{2}$ KIMATA, DM; ${ }^{3}$ KWEYU, RA}

\author{
${ }^{I}$ Wangari Maathai Institute for Peace and Environmental Studies, ${ }^{2}$ School of Biological Sciences, University of Nairobi, PO Box 30197 - \\ 00100 GPO Nairobi, Kenya \\ ${ }^{3}$ Department of Geography, Kenyatta University, PO Box 43844 - 00100, Nairobi, Kenya

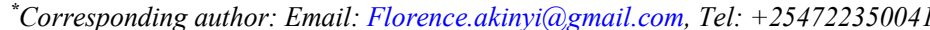

\begin{abstract}
Waste management predicaments in attaining sustainable city status globally is challenged by increased solid waste generation as a result of rapid urban population and migration. Through a critique lens, solid waste management predicaments in developing countries characterized by inefficiencies; weak institutional capacities and lack of financial prudence. Nairobi City illustrates vividly predicaments through sporadic growth of open dumpsites, blocked drainers and sewers, indiscriminate behavior of littering. This is aided by weak enforcement of solid waste policies and regulations, duplicity of mandates by institutions and limited human resources. This paper undertakes to explicate predicaments in Nairobi City County and is supported by institutional, capacity and planned behavior theories. The study adopted mixed research design with data collection from a sample size of 385 household. Primary and secondary data was collected using questionnaires, key informant interview and focus group discussion; transect walk and desk top analysis. The results support the critique as documented by this paper. The study recommends institutional empowerment to reverse negative predicaments for sustainable global cities.
\end{abstract}

DOI: https://dx.doi.org/10.4314/jasem.v24i10.14

Copyright: Copyright (C) 2020 Ogutu et al. This is an open access article distributed under the Creative Commons Attribution License (CCL), which permits unrestricted use, distribution, and reproduction in any medium, provided the original work is properly cited.

Dates: Received: 15 August 2020; Revised: 22 September 2020; Accepted: 19 October 2020

Keywords: critique, sustainable cities, waste management, predicaments, Nairobi City, Kenya

Sub - Saharan Africa is faced with significant predicaments of waste management challenges of providing universal access to waste collection services and dysfunctional policies and regulations on SWM. Sustainable cities require functional SWM systems for them to be resilient, offering job opportunities, fighting poverty, challenging due to WM predicaments (UNEP, 2015; UNEP and ISAWA, 2015). The rapid population growth rate, spur in urbanization, industrialization, and economic growth, has accelerated increased waste generation globally, especially in cities (urban areas). Notably, in SubSaharan Africa, notwithstanding Nairobi City County, per capita waste generation has increased for the last many years, which transforms to five to six times higher than in developed countries (Godfrey et al., 2019a; UNEP, 2018). The World Bank projection shows that the urban population in developing countries will double from 2 to 4 billion between 2000 and 2030. Thus translating to 2.01 billion tonnes of municipal solid waste will be generated yearly and to managed that trash in a sustainable way is problematic, especially in developing countries (Kaza et al., 2018; World Bank, 2018a). Additionally, UNDP approximates that the growth of the world population will remain in the cities of the less developed regions
(UN, 2017). However, developing countries, for instance, Nairobi, have not effectively implemented sustainable, robust waste management systems that are proportionate with the increase of solid waste generation (Guerrero et al., 2013; UNDP, 2016a). Unsustainable waste management is one of the predicaments that have overwhelmed Nairobi City County. NCC's solid waste management methods remain challenged by high urban population growth and increased solid waste generation; this disparity has resulted in the overall weak solid waste management system, impediment to the realization of sustainable cities (UNDP, 2016b). Solid waste management in Nairobi County is problematic, dogged by ineffective collection systems, inadequate coverage of the collection system, and disposal systems are not environmentally friendly; direct dumping and burning of waste without proper inspection and separation (sorting), and scavenging. Treatment of waste hardly done, and a small percentage of the waste is processed, which leads to a growing culture of uncontrolled dumpsites (Kimani, 2007; Njoroge, et al., 2012). Insufficient financial capacity for waste management; thus, the costs are never fully recovered compounded by weak institutional structures and weak enforcement of the policies related to solid waste management 
(Gakungu, et al., 2012; Ogutu, 2019; UNEP and UNHABITAT, 2009).

Solid waste management is a visible urban service, and its practical and sustainable management provides an indicator for SWM local good governance, which is related to the performance of municipal authorities. Research suggests that sustainable waste management can address the predicaments of unsustainable waste management in cities globally, Nairobi City included (NEMA, 2014; UNEP, 2005). Nairobi City County, insufficient solid waste management frameworks, involved an array of predicaments from governance failure, deficiency in public awareness and knowledge, inadequate infrastructure, and low technical and institutional capacities (Karak et al., 2012; Van Wyk and Dlamini, 2018). Also, SWM in NCC must incorporate effective environmental SWM structures involving guidelines, procedures, also performance whereby welfares are taken care of, resources are managed, and power is exercised whose consequences are proactive in addressing the challenges brought by unsustainable solid waste management (Adebayo Bello and bin Ismail, 2016; Kazungu, 2010; UN-HABITAT, 2010). Thus, sustainable waste management should include practical, implemented, and well-enforced laws and regulations, effective and accountable institutions that can foster mechanisms of reducing the predicaments of unsustainable solid management (Ezechi et al., 2017; Henry et al., 2006).

There should exist an enabling environment for appropriate incorporation and combined application of local and international conventions, policies, and environmental administrative structures that foster efficiency of service delivery and strengthening capacity building in terms of financial, institutional, technological, and infrastructural (Al-Khatib et al., 2015; Guerrero et al., 2013). Organizations authorized with the responsibility of ensuring that proper values that govern SWM within a decision-making process of their nations/cities and individuals are vital (UNEP, 2016). Anthropological activities generate waste, which can be harmful to the environment, ecosystems, animals, plants, indicating negative ecological impacts of unsustainable SWM. However, only sound SWM governance can reverse the damage done to the environment (Achere, 2012; McAllister, 2015; Winqvist et al., 2013). The burgeoning problems of SWM predicaments in Nairobi County of continuous population growth, changes in lifestyle, economic development, accelerating increased solid waste generation, an obstacle for the county authorities and other service providers to provide sustainable solid waste management services, evident in other developing countries (International Solid Waste Association (ISWA), 2017; Otieno, 2010; Oyake, 2012). SWM systems lack the capacity in terms of funds, human resources, and technological inadequacies, lack of coordination of operational processes, inadequate WM infrastructure, insufficient disposal space, lack of public awareness and knowledge on environmental stewardship, a challenge to respond to the changing situation, thus unsustainable solid waste management (Andole, 2016; JICA, 2014, 2010; Kasala, 2014; Mutisya and Yarime, 2011). Waste management systems should include the role of the state in society through assimilating all stakeholders, from waste generation stage to waste disposal stage, and involved the public, private, civil society, and community sectors (Fukuyama, 2013; Godfrey et al., 2019a; Ikebude, 2017). Consequently, this will address the inadequate infrastructure, financing, lack of clear roles and responsibilities of the urban authorities, improper waste collection and disposal systems which are challenging, hence public health and sanitation are threatened (dos Muchangos et al., 2014; Muniafu and Otiato, 2010; World Bank, 2018a). The predicament in ensuring effective and proper SWM systems critical to the achievement of Sustainable Development Goals (SDGs); thus, sustainable cities is a challenge in Africa. At the household level, enormous functional solid waste generated every day; end up in the environment wetlands and impacting negatively, polluting water sources and posing significant health hazards to human beings and the environment. This situation is not different from other developing countries as supported by other authors (Chuen et al., 2011; Godfrey et al., 2019b; Jain and Jain, 2020; Ogutu, 2019; Sibanda et al., 2017; World Bank, 2018b). The objective of this study was to critique SWM predicaments in Nairobi City County.

\section{MATERIALS AND METHODS}

Nairobi City County is the capital of the Republic of Kenya, and Africa's most dynamic City, the largest administrative, commercial, and industrial Centre and the heartbeat of Kenya's economy, produces over $60 \%$ of the Country's GDP (United Nations Environment Programme (UNEP) and UN-HABITAT, 2007). The population of Nairobi City County stands at 4.397 million, accelerating increased solid waste generation, and environmental burden and challenge for the City (Kenya National Bureau of Statistics (KNBS), 2019).

The City is globally connected and a famous destination, regionally and locally, it has been ranked as the $80^{\text {th }}$ most visited City in the world. It is an established hub for business, culture, education, and a global cuisine hub, with many hotels of different 
cultures towering the population. It is a unique city in the world with a National Park within the City. Government ministries who formulate laws on environmental management are based in Nairobi and include NEMA, ministry of environment, and natural resources. Nairobi's strategic international location reinforces its importance as a diplomatic, commercial and cultural centre in Africa; thus, Nairobi warrants protection environmentally speaking in SW to regain its lost glory, once referred to as the Green City in the sun (Ikiara, 2006; Nairobi Metro 2030, 2008).

The study adopted a mixed study design, and data collection tools used were desktop analysis for secondary data and surveys for primary data. Data collected by the administration of semi-structured questionnaires, supplemented by key informant interviews (KIE), focus group discussion (FGD), and transect walks on the sampled sub-counties of Lavington, Kibra and Embakasi. Field surveys played a critical role in recording and accumulating information on the exact ground locations in Nairobi County. Also, the Digital Globe satellite image website used to upload the shape-file of NCC for the identification of the area of study (Walter, 2018).

A target population of 385 households randomly selected from a sampling method that gives an equal representation of the samples. Data were analyzed quantitatively using SPSS version 24 and qualitatively based on the emerging themes (Mugenda and Mugenda, 2008; Williams, 2011).

A theoretical framework based on institutional, capacity, and planned behavior theories supported the study. Institutional and capacity building theories used to expound on sustainable cities' waste management predicaments. Institutional theory, based on the interaction of the three pillars, includes; regulative, normative, and cognitive that can either limit or support the operation of organizations (Scott, 1995). Regulative deals with policies, legal systems, and obligations, which include fear, coercion. Normative involves duties and responsibilities, moral obligations, and norms. Cognitive deals with cultural methods, values, beliefs, and personal desires (Delbridge and Edwards, 2013a).

These pillars determined the behaviour of individuals as they cooperate in their activities, social, economic, and political. Concerning SWM, in terms of waste handling, policies are in place, the way the different actors interact in an institutional structure; either together or incoherent, can influence the management to either success or failure of SWM systems (Delbridge and Edwards, 2013b; Wilson et al., 2013; Wilson and Velis, 2015).
Capacity building theory involves empowering institutions, individuals, and communities to execute functions and solve problems to attain the progress of their goals satisfactorily (UNEP, 2002a; UNEP and ISAWA, 2015). Inadequate capacity is an obstacle to sustainable SWM in many urban centres of subSaharan Africa (UNEP, 2002b). A practical and durable municipal reliable waste management systems entail building management capacity from the local authority personnel, key stakeholders, technical, financial, and regulatory for operating, maintaining, and supervising the process (UNEP, 2002b). However, many workers in the SWM, including government institutions, private sector, NGOs, and CBOs, have inadequate technical, regulatory, and financial capacities to operate effectively, illustrating WM predicaments, especially in developing countries, NCC included (UNEP, 2002b).

The theory of planned behaviour serve in predicting and understanding human behaviour, defines the relationship between attitude and behaviour concerning pro-environmental practice and environmental knowledge in solid waste management (Ajzen, 1991). The theory postulates that three factors guide the purpose to accomplish an act; subjective norm, individual's attitude, and perceived behavioural control - individual's actions of a specific behaviour (is it the worthy or wrong thing to do?). Attitude defined as a "function of salient beliefs at a given point in time" (Ajzen and Fishbein, 1980; Fishbein and Ajzen, 1975). Subjective norm, it's an individual's belief and the behaviour will be judged by others (what do others think 1 should do?) and lastly perceived behavioural control indicates that the individual recognizes that they can control the behaviour (can 1 do it?) (Ajzen, 1991). This theory is relevant to this study; public awareness and environmental values and ethics are lacking, leading to unsustainable solid waste management disposal practices. Most people in NCC are not conscious when it comes to waste management; this illustrated by the culture of littering evident in the mushrooming of unplanned dumpsites in NCC (Otieno, 2010; UNEP, 2015; Ogutu, 2019). Positive attitude to solid waste management through education and public awareness by relevant institutions result in responsible behaviour towards the environment, thus they will have a positive attitude towards the act to do so (Ajzen, 1991). Additionally, when the public embraces the behaviour of complying to the polices in solid waste management, like minimizing waste generation, segregation of waste at source, no littering, among others, this would mitigate adverse effects on the environment, ; thus they will have a positive attitude towards the behaviour to do so (Stern, 2000). 


\section{RESULTS AND DISCUSSION}

The data illustrates the predicaments of waste management in Nairobi City County in that the number of illegal dumpsites in Embakasi and Kibra increasing rapidly unlike Lavington. The population in these regions demonstrates predicaments of waste management when the institutions are not well equipped in policy implementation. The majority of respondents in NCC agreed that waste management policies play a vital role in addressing SWM predicaments in NCC.

They concur that the effectiveness of the strategies is in enforcement implementation. Penalties and rewards will enhance positive WM behavior and discourage the culture of littering in NCC. The majority of the respondents concur that waste management predicaments in the form of improper disposal, from the rising number of uncontrolled dumpsites, affect the environment; blocked drainers and sewers result in poor sanitation, which impacts negatively on public health and frequent disease outbreak.

The majority of the respondents had an optimistic viewpoint on waste minimization through the culture of 3Rs- Reduce, Reuse, and Recycle. They agreed that would foster positive Waste Management Predicaments for a waste-free environment, accelerating sustainable waste management in NCC. The willingness to adopt the $3 \mathrm{R}$ culture would impact positively on the predicaments of waste management in Nairobi City County which can be useful in curtailing illegal dumpsites.

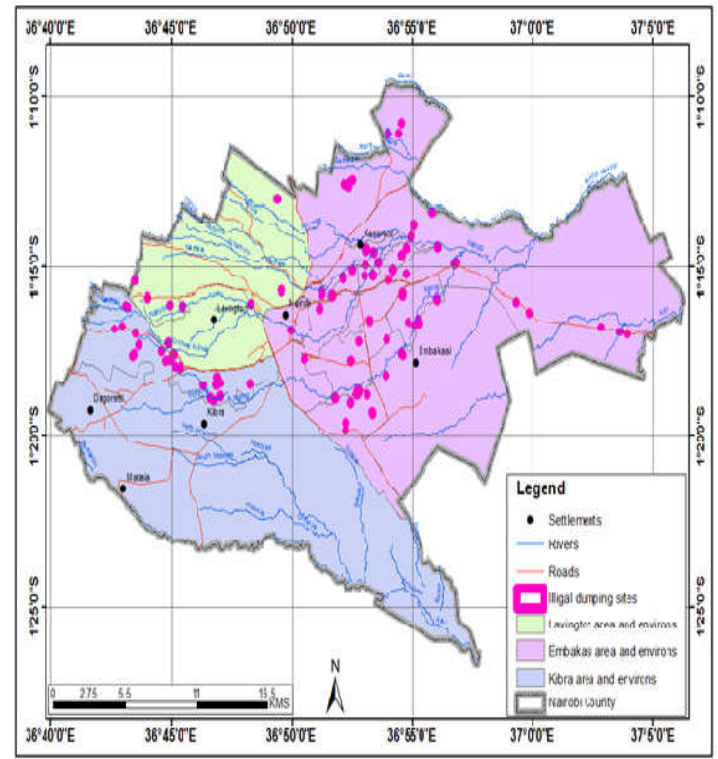

Fig. 1: Study area Map showing predicaments of waste management in Nairobi City County.

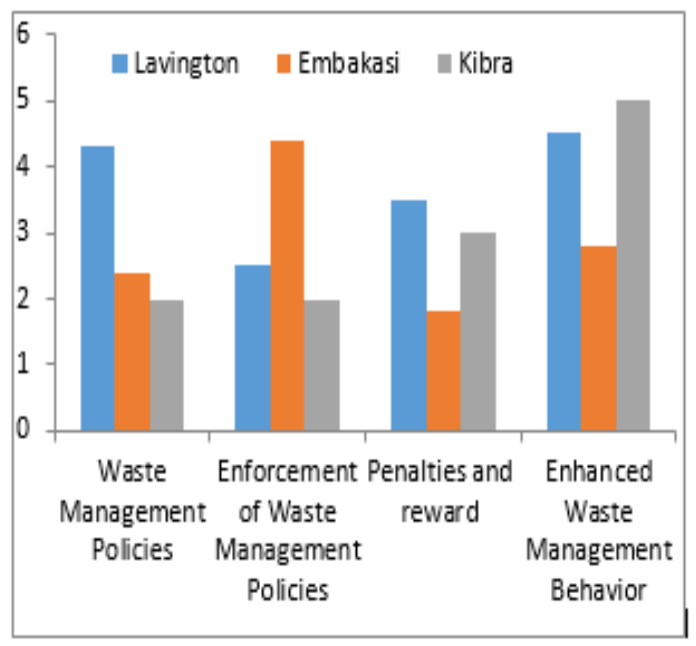

Fig 2: Role of Waste Management Policies to Influence the predicaments in Nairobi City, Kenya

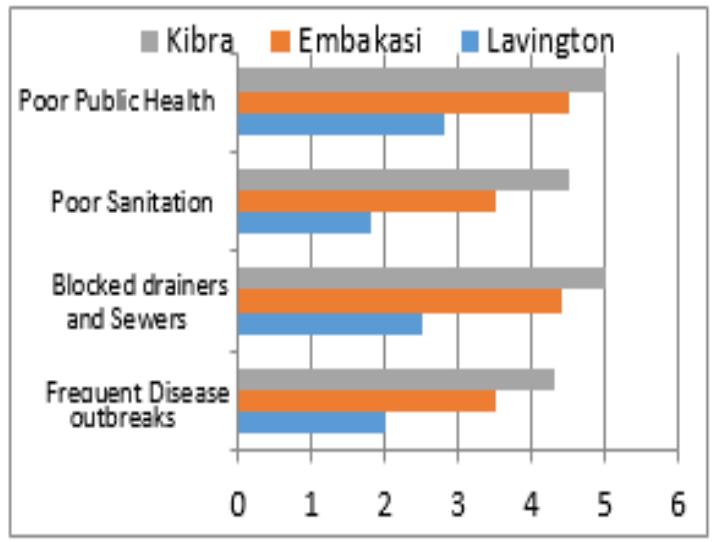

Fig 3: Impacts of Waste Management Predicaments on Environmental Health in Nairobi, Kenya

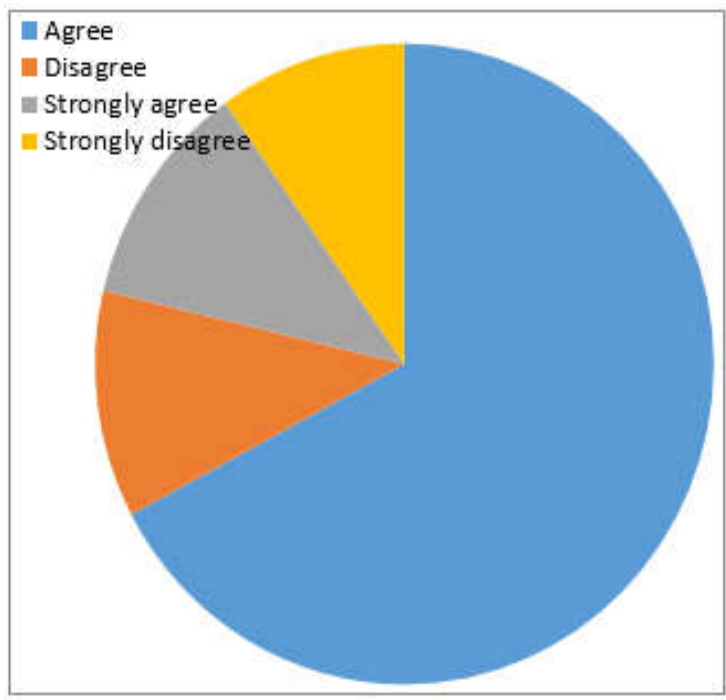

Fig 4: Culture of 3Rs- Reduce, Reuse and Recycle Foster Positive Waste Management Predicaments in Nairobi, Kenya 


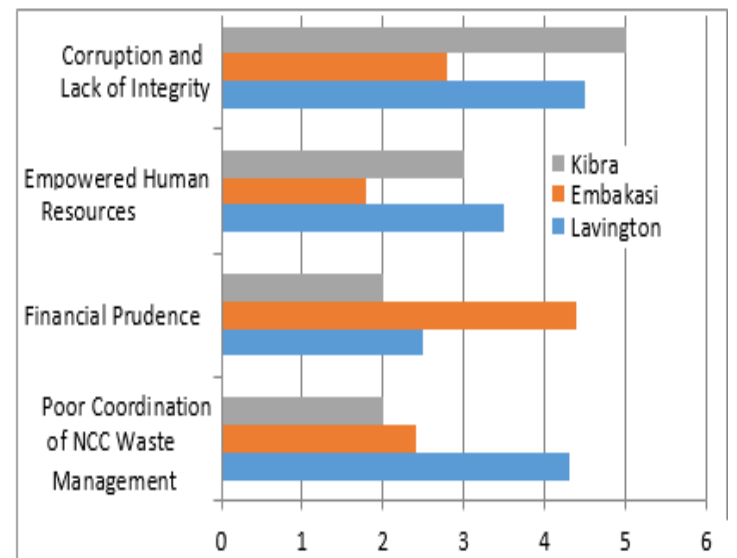

Fig 5: Factors influencing Negative Waste Management Predicaments in Nairobi, Kenya

The majority of the respondents from the three subcounties, Kibra, Embakasi, and Lavington, agreed that factors accelerating adverse waste predicaments, corruption and lack of integrity, financial prudence, inadequate empowered human resources, and poor coordination of NCC WM, thus unsustainable SWM system in NCC. Nairobi is the most populated County, with a population of 4.8 million people, very high growth rate compared to many cities in developing and developed countries (Kenya National Bureau of Statistics (KNBS), 2019; UNEP, 2018). The fast population growth attributed to several reasons and include; rural-urban migration in pursuit of employment prospects, business opportunities, and other factors that attract residents to the City (Hoornweg and Bhada, 2012). Increased population growth rate accelerates waste management predicaments, an impediment to environmentally sound WM (Allison and Von Blottnitz, 2010). Unsustainable waste management in the city has been an ignored subject, not considered in planning aimed at sustainable, healthy, and inclusive cities and communities. As the population increased, very minimal institutional reforms made, and NCC struggles with good SWM governance. Therefore, waste that is not collected is one of the greatest, visible, and most challenging Nairobi's environmental predicaments. Solid waste generation has remained on the increase, with the highest urban growth rate in the world, at 8.5 percent (Kenya National Bureau of Statistics (KNBS), 2019; UNEP, 2018, 2015). The county government cannot manage, have caused global attention at 2,700 tons of waste produced each day, compared to Addis Ababa Ethiopia, who has the same population size, only generates 1,680 tons per day (Ayobami et al., 2016; Ogutu, 2019; Oyake, 2018; UNEP, 2012, p. 2012; World Bank, 2018a). The majority of the respondents agreed that WM policies play a pivotal role in addressing SWM predicaments in NCC, and its effectiveness is in enforcement and implementation. There is a lack of enough supporting legal framework to accommodate the challenges of SWM. Nairobi's status fundamentally characterized by numerous inefficiencies, low coverage of solid waste collection, pollution from uncontrolled dumping of waste, impact on public health and the environment, inefficient public services, weak enforcement of SWM policies and regulations, limited funding, unregulated and uncoordinated private sector, and lack of key solid waste infrastructure (Gakungu, et al., 2012; Haregu et al., 2017; JICA, 2010; NEMA, 2014; Satterthwaite, 2015). The Kenyan 2010 constitution has devolved SWM governance to the 47 counties through the County Government Act of 2012, provided a framework for the counties and their county assemblies to formulate policies/regulations/acts in the Management of SW in their respective counties (Government of Kenya GOK, 2010). Nairobi County has instituted various policies and laws on SWM; despite this, sustainable SWM remains a challenge. This is supported by the majority of the respondents from the three sub-counties, Kibra, Embakasi, and Lavington agreed that factors accelerating adverse waste predicaments, corruption and lack of integrity, cartels, financial prudence, inadequate empowered human resources, and weak coordination mechanism of SWM., thus unsustainable SWM system and a global city like NCC, should be geared to sustainable city status (Ferronato and Torretta, 2019; Kaza et al., 2018; Ogutu, et al., 2018). Additionally, SWM services are skewed where the low and middle-income areas, have dysfunctional waste collection system, and they have no option but to dispose of their waste indiscriminately; while the high-income areas, private waste collection companies collect the waste and residents pay for the services without really knowing where the waste will end, enabling factors in enhancing the growth of uncontrolled dumpsites (Haregu et al., 2017; Maton et al., 2016; Ogutu, 2019; UNDP, 2017, 2016b). The data from the results support the respondent's views that positive waste management behaviour, where the individuals care for the environment is lacking, strategies for empowering the residents of NCC is limited. This is further supported by unlawful littering of waste in open spaces, drains, and gutters, impacting negatively on the environment and human health (Bailey, 2015; Geissdoerfer et al., 2017; Ross, 2011; UN-HABITAT, 2011; Wilson and Velis, 2015). However, all is not lost; there are limited public education and awareness campaigns carried by NGOs, Church organizations, and the media. Also, NCC does carry out environmental clean-ups at the grassroots, litter bins branded with ecological messages, to enhanced awareness efforts. Additionally, the new curriculum, 
of 2-6-6-3, competency-based curriculum, introduced environmental education from preschool; these initiatives will go a long way to instill positive behavior towards the environment (Ogutu, et al., 2019; Oyake, 2018).

Nairobi City County erratic growth of uncontrolled dumpsites explicate waste management predicaments and are as a result of an overstretched legal dumpsites by the increased waste generated due to high population growth rate and unsustainable WM system. One negative predicament is overstretched legal dumpsite of Dandora which serves other serves other metropolitan towns like Kajiado, Kiambu, and Machakos. Additionally, the dumpsite is enclosed by several housing estates and slums, a health and environmental disaster that affects the health of people living there and pollutes the Nairobi River, as revealed by a study done by UNEP, 2007 (Gumbihi, 2013; Henry et al., 2006; Kimani, 2007). Report by UNEP (2016), studies conducted by different urban planning experts recommended that the dumpsite relocated to the nearby Ruai area. This was because the area had plenty of space to supplement the increasing waste generated by the City residents, which has not been effected to date due to weak institutional structures to deal with solid waste management efficiently (Kenya National Bureau of Statistics (KNBS), 2015; Oyake, 2012; Rodić and Wilson, 2017; UNEP, 2005). Global waste management outlook focus shifted from waste disposal to address the problem from the source through preventing its generation, adopting 3Rs culture- reduce, reuse and recycle, geared towards a circular economy and sustainable SWM and environmental protection (Sakijege, 2019; UNEP and ISAWA, 2015; Xiao et al., 2020). Policies and regulations on solid waste management in $\mathrm{NCC}$ are inclined towards the collection, transportation and disposal, with the least emphasis on recycling and reuse, illustrating WM predicaments. NCC lack properly integrated SWM systems; thus, the implementation of 3Rs a challenge and waste minimization is limited, mostly done by informal sectors; recycling at $8 \%$ and resource recovery $6 \%$ (Nairobi Metro 2030, 2008; Ogutu, et al., 2019). This compounded by Public attitude towards waste management and lack of empowerment on environmental values and ethics by the relevant institutions, thus waste is not seen as a resource to be exploited (NEMA, 2014; Ogutu, et al., 2018; Xiao et al., 2020). Waste can provide a source of opportunities, composing for bio fertilizers, energy, employment, private investments. This is supported by the respondents who agreed that effective implementation of the 3Rs culture would foster positive waste Management Predicaments for a waste- free environment, accelerating sustainable waste management in NCC (Ferronato et al., 2019; Ferronato and Torretta, 2019; Jain and Jain, 2020). Previous studies on this subject show that developed countries have institutionalized 3Rs culture for the circular economy, thus overcoming challenges of unsustainable SWM (Ferronato and Torretta, 2019). The future of sustainable SWM for sustainable cities globally can be enhanced by improving SWM policy implementation at all levels of stakeholders' involvement. Effective and accountable policy frameworks and implementation strategies, SWM education, and creation of public awareness on environmental stewardship empowered institutions and maximizing popular participation in service delivery (Godfrey et al., 2019a; Maton et al., 2016; Xiao et al., 2020). WM predicaments illustrate the failure to effectively implement policies and regulations on solid waste management with institutions dealing with substantial waste management lack synergy resulting in a lack of coordination and inefficiency as this paper documents (Troschinetz and Mihelcic, 2009).

Conclusion: Waste management predicaments show the challenges of unsustainable SWM in Nairobi City County and elucidate the potential negative impacts it has on public health, economy, and the environment. The paper brings out the importance of collaboration among institutions in enhancing sustainable SWM for sustainable cities and managing adverse effects from poor waste management. The future of sustainable SWM system should focus on equity, participation, pluralism, transparency, accountability, and the rule of law done in a manner that is effective, efficient, and enduring.

Acknowledgments: I would like to acknowledge support and guidance from professor Elly Otieno Ogutu, Dr. Bessy Kathambi, and my family members.

\section{REFERENCES}

Achere, R. (2012.) Solid Waste Management: A world perspective and the Cameroon case study. Universidad Fernando Pessoa, Portugal.

Adebayo Bello, I., bin Ismail, M.N. (2016) Solid Waste Management in Africa: A Review. Int J Waste Resour 6.

Ajzen, I. (1991). The theory of planned behavior. Organizational Behavior and Human Decision Processes 50, 179-211. 
Ajzen, Icek, Fischbein, M. (1980) Understanding attitudes and predicting social behavior. PrenticeHall.

Al-Khatib, I.A., Kontogianni, S., Nabaa, A.H., Alshami, N., Al-Sari, M.I. (2015). Public perception of hazardousness caused by current trends of municipal solid waste management. J. Waste Manage 323-330.

Allison, K., Von Blottnitz, H. (2010). Solid waste management in Nairobi, a situational analysis, technical document accompanying the integrated solid waste management plan. UNEP, Nairobi.

Andole, O.H. (2016). The state of solid waste management in Kenya. JKUAT, Kenya.

Ayobami, P., Ayangbile, O.A., Banji, A. (2016). Assessment of solid waste management systems in Ibadan North, Oyo State using geo-spatial techniques. Ethiopian Journal of Environmental Studies and Management.

Bailey, R. (2015). Solid waste management in the world's cities. UN-Habitat's third global report on the state of water and sanitation in the world's cities. UN-HABITAT.

Chuen, K.P., Lim, Y.M., Choong, C.K. (2011). Household demand for solid waste disposal options in Malaysia. University Library of Munich.

Delbridge, R., Edwards, T. (2013a). Inhabiting Institutions: Critical Realist Refinements to Understanding Institutional Complexity and Change. Organization Studies 34, 927-947.

Delbridge, R., Edwards, T. (2013b). Inhabiting Institutions: Critical Realist Refinements to Understanding Institutional Complexity and Change. Organization Studies 34, 927-947.

dos Muchangos, L.S., Liu, Y., Li, B. (2014). Comparative study on municipal solid waste management systems of Maputo City, Mozambique and Chongqing City, China. African Journal of Science, Technology, Innovation and Development 6, 323-331.

Ezechi, E.H., Nwabuko, C.G., Enyinnaya, O.C., Babington, C.J. (2017). Municipal solid waste management in Aba, Nigeria: Challenges and prospects. Environmental Engineering Research 22, 231-236.

Ferronato, N., Ragazzi, M., Gorritty Portillo, M.A., Guisbert Lizarazu, E.G., Viotti, P., Torretta, V. (2019.).How to improve recycling rate in developing big cities: An integrated approach for assessing municipal solid waste collection and treatment scenarios. Environmental Development 29, 94-110.

Ferronato, N., Torretta, V. (2019). Waste Mismanagement in Developing Countries: A Review of Global Issues. IJERPH 16, 1060.

Fishbein, M., Ajzen, I. (1975.).Belief, Attitude, Intention, and Behavior: An Introduction to Theory and Research.

Fukuyama, F. (2013). What is Governance?

Gakungu, N.K., Njoroge, B.N.K., Kimani, M.W. (2012). Solid waste management in Kenya: A case study of public technical training institutions. J. Eng 127-138.

Geissdoerfer, M., Savaget, P., Bocken, N.M.P., Hultink, E.J. (2017). The Circular Economy - A new sustainability paradigm? Journal of Cleaner Production 143, 757-768.

Godfrey, L., Tawfic Ahmed, M., Giday Gebremedhin, K., H.Y. Katima, J., Oelofse, S., Osibanjo, O., Henning Richter, U., H. Yonli, A. (2019a.). Solid Waste Management in Africa: Governance Failure or Development Opportunity? In: Regional Development in Africa [Working Title]. IntechOpen.

Godfrey, L., Tawfic Ahmed, M., Giday Gebremedhin, K., H.Y. Katima, J., Oelofse, S., Osibanjo, O., Henning Richter, U., H. Yonli, A. (2019b). Solid Waste Management in Africa: Governance Failure or Development Opportunity? In: Regional Development in Africa [Working Title]. IntechOpen.

Government of Kenya GOK, 2010. Constitution of Kenya.

Guerrero, L.A., Maas, G., Hogland, W. (2013). Solid waste management challenges for cities in developing countries. Waste Management 33, 220-232. 
Gumbihi, H. (2013) Lords of the flies: unmasking Dandora's trash lords. Standard Newspaper.

Haregu, T.N., Ziraba, A.K., Aboderin, I., Amugsi, D., Muindi, K., Mberu, B. (2017). An assessment of the evolution of Kenya's solid waste management policies and their implementation in Nairobi and Mombasa: analysis of policies and practices. Environment and Urbanization 29, 515-532.

Henry, R.K., Yongsheng, Z., Jun, D. (2006). Municipal solid waste management challenges in developing countries - Kenyan case study. Waste Management 26, 92-100.

Hoornweg, D., Bhada, T. (2012) what a waste: A global review of solid waste management. In: Urban Development Series Knowledge Papers. World Bank.

Ikebude, C.F. (2017). Feasibility Study On Solid Waste Management In Port Harcourt Metropolis: Causes, Effect And Possible Solutions. African Journals OnLine (AJOL) 36.

Ikiara, C. (2006). Opportunities and challenges in privatizing urban environmental infrastructure: Lessons from the Dandora dumpsite Nairobi. Presented at the workshop on public expenditure and service delivery in Africa: Managing public expenditure to improve service quality, Uganda.

International Solid Waste Association (ISWA). (2017).Annual review report: Working together towards a cleaner, healthier planet. International Solid Waste Association (ISWA).

Jain, T.K., Jain, N (2020). Urban Production and Consumption. In: Leal Filho, W., Marisa Azul, A., Brandli, L., Gökçin Özuyar, P., Wall, T. (Eds.), Sustainable Cities and Communities, Encyclopedia of the UN Sustainable Development Goals. Springer International Publishing, Cham, pp. 915-923.

JICA. (2010). Preparatory survey for integrated solid waste management in Nairobi city in the Republic of Kenya. JICA, Nairobi.

JICA, 2014. The study of Solid waste management in Nairobi City. JICA, Nairobi.

Karak, T., Bhagat, R.M., Bhattacharyya, P. (2012.).Municipal Solid Waste Generation,
Composition, and Management: The World Scenario. Critical Reviews in Environmental Science and Technology 42, 1509-1630.

Kasala, S.E. ((2014). Critical Analysis of the Challenges of Solid Waste Management Initiatives in Keko Machungwa Informal Settlement, Dar es Salaam. JEP 05, 1064-1074.

Kaza, S., Yao, L., Bhada-Tata, P., Van Woerden, F., 2018. What a Waste 2.0: A Global Snapshot of Solid Waste Management to 2050. The World Bank.

Kazungu, R.K., 2010. Improving governance for sustainable solid waste management in Nairobi, 46th ISOCARP Congress. ISOCARP, Nairobi.

Kenya National Bureau of Statistics (KNBS), 2015. Kenya Facts and Figures. Kenya Bureau of Statistics KNBS, Kenya.

Kenya National Bureau of Statistics (KNBS), 2019. Population and house results. Kenya Bureau of Statistics KNBS, Kenya.

Kimani, N.G., 2007. Environmental pollution and impacts on public health: Implications of the Dandora municipal dumping site in Nairobi, Kenya. UNEP, Nairobi.

Maton, D.J., Kigun, P.A., Ogalla, M., 2016. Integrated solid waste management: a palliative to existing waste management challenges in Jabi-District, Abuja. Ethiopian Journal of Environmental Studies and Management 9, 769-779.

McAllister, J., 2015. Factors Influencing Solid-Waste Management in the Developing World.

Mugenda, M.O., Mugenda, G.A., 2008. Social Science Research: Theory and Principles. Acts Press, Nairobi, Kenya.

Muniafu, M., Otiato, E., 2010. waste management in Nairobi, Kenya. A case for emerging economies.

Mutisya, E., Yarime, M., 2011. Understanding the Grassroots Dynamics of Slums in Nairobi : The Dilemma of Kibera Informal Settlements. 2, 197213. 
Nairobi Metro 2030, 2008. Ministry of Nairobi Metropolitan Development. Nairobi Metro, Nairobi.

NEMA, 2014. The national solid waste management strategy.

Njoroge, B.N.K., Kimani, M.W., Ndunge, D.A., 2012. Review of municipal solid waste management: A case study of Nairobi, Kenya. Int. J. Eng. Sci.

Ogutu, F.A. (2019).Assessment of the effectiveness of the policy framework in solid waste management in Nairobi city county. University of Nairobi, Nairobi.

Ogutu, F.A., Kimata, D., Kweyu, R. (2018). Factors affecting the use of environmental values and ethics in solid waste management in Nairobi city county. International Journal of Environmental and Health Sciences 1.

Ogutu, F.A., Kimata, D., Kweyu, R. (2019). The Role of Environmental Governance in Solid Waste Management, Policy Implementation in Nairobi County. CER.

Otieno. (2010). Storm clouds of our solid waste may blow us away if we don't act now. Daily Nation Newspaper.

Oyake, L.O. (2012). plastics waste in urban Kenya, niche innovations in production, and recycling. Wageningen University, Netherlands.

Oyake, L.O. (2018). How Nairobi, Kenya fixes its waste management problem. Quartz Africa, Nairobi.

Rodić, L., Wilson, D. (2017). Resolving Governance Issues to Achieve Priority Sustainable Development Goals Related to Solid Waste Management in Developing Countries. Sustainability 9, 404.

Ross, D.E. (2011). Safeguarding public health, the core reason for solid waste management. Waste Manag Res 29, 779-780.

Sakijege, T. (2019). Repercussions of Improved Municipal Solid Waste Management on Flood Risk Reduction: The Case of Dar es Salaam, Tanzania. GEP 07, 177-199.
Satterthwaite, D. (2015). Topic Guide: Urban poverty, urban pollution and environmental management. Evidence on Demand.

Scott, W.R. (1995).Institutions and Organizations. Ideas, Interests and Identities. Sage.

Sibanda, L.K., Obange, N., Awuor, F.O. (2017). Challenges of Solid Waste Management in Kisumu, Kenya. Urban Forum 28, 387-402.

Stern, P.C. (2000). Toward a Coherent Theory of Environmentally Significant Behavior.

Troschinetz, A.M., Mihelcic, J.R. (2009). Sustainable recycling of municipal solid waste in developing countries. Waste Management 29, 915-923.

UN. (2017). World population Prospects, 2017 revision Population database. UN.

UNDP. (2016a). sustainable urbanization strategy, s support to sustainable, inclusive, and resilient cities in the developing world. UNDP.

UNDP. (2016b). Nationally appropriate mitigation action on a circular economy, solid waste management approach for urban areas in Kenya. UNDP.

UNDP. (2017). Sustainable Development Goals: Post2015 Localizing SDGs in Kenya: Building on the Lessons Learned of the MDGs. What Role Can the UN System Play in the Process?

UNEP. (2002a). Capacity building for sustainable development: an overview of UNEP environmental capacity development initiatives. UNEP.

UNEP. (2002b). Capacity Building for Sustainable: An Overview of UNEP Environmental Capacity Development Activities.

UNEP. (2005). Selection, design, and implementation of economic instruments in the solid waste management sector in Kenya: The case of plastic bags. UNEP, Nairobi.

UNEP. (2012). Global environmental outlook 5: environment for the future we want. UNEP, Nairobi. 
UNEP, 2015. Global Waste Management Outlook. UNEP.

UNEP. (2016). Frontiers report emerging issues of environmental concern. UNEP, Nairobi.

UNEP, 2018. Africa waste management outlook. UNEP, Nairobi.

UNEP, ISAWA. (2015). Global Waste Management Outlook. Osaka: United Nations Environment Programme. UNEP/ ISAWA, Osaka.

UNEP, UN-HABITAT. (2009). City of Nairobi environment outlook, Nairobi, Kenya. UNEP/ UN-HABITAT, Nairobi.

UN-HABITAT, 2010. Solid Waste Management in the World Cities: Water and sanitation in the world's cities.

UN-HABITAT. (2011). Collection of Municipal Solid Waste: Key issues for Decision-makers in Developing Countries. UN-HABITAT, Kenya.

United Nations Environment Programme (UNEP), UN-HABITAT. (2007). City of Nairobi environment outlook, Nairobi, Kenya. UNEP/ UN-HABITAT, Nairobi.

Van Wyk, R.B., Dlamini, C.S. (2018). The impact of food prices on the welfare of households in South Africa. SAJEMS 21.

Walter, S. (2018). Digital Globe.
Williams, C. (2011). Research Methods. JBER 5.

Wilson, D.C., Velis, C.A. (2015). Waste management - still a global challenge in the 21st century: An evidence-based call for action. Waste Manag Res 33, 1049-1051.

Wilson, D.C., Velis, C.A., Rodic, 1. (2013). Integrated sustainable waste management in developing countries. Proceedings of the Institution of Civil Engineers - Waste and Resource Management $166,52-68$.

Winqvist, G.Ö., Slunge, D., Sverige, Naturvårdsverket, United Nations Development Programme. (2013). Governance bottlenecks and policy options for sustainable materials management: discussion paper. Swedish Environmental Protection Agency, Stockholm.

World Bank.(2018a). Solid waste management. World Bank.

World Bank. (2018b).What a waste: An updated look into the future of solid waste management. World Bank.

Xiao, S., Dong, H., Geng, Y., Francisco, M.-J., Pan, H., Wu, F. (2020). An overview of the municipal solid waste management modes and innovations in Shanghai, China. Environ Sci Pollut Res 27, 29943-29953. 